\title{
Revista
}

Triângulo

\section{EDUCAÇÃO PARA AS RELAÇõES ÉTNICO-RACIAIS E FORMAÇÃO DOCENTE: DILEMAS E PERSPECTIVAS}

\section{EDUCATION FOR ETHNIC-RACIAL RELATIONS AND TEACHER TRAINING: DILEMMA AND PROSPECTS}

\author{
Wilker Solidade e Eugênia Portela de Siqueira Marques
}

\begin{abstract}
RESUMO
Este trabalho discute os procedimentos metodológicos e os resultados parciais de uma pesquisa acerca das Políticas Públicas para a Educação das relações étnico-raciais a partir das possibilidades abertas pela Lei 10.639/2003 que alterou a LDBENEN e tornou-se imperativo educativo a História da África e da Cultura afrobrasileira nos sistemas de ensino do Brasil. Tece considerações sobre a efetivação de práticas pedagógicas voltadas para o reconhecimento e o respeito à diversidade étnico-racial, à superação da discriminação racial e a afirmação da identidade da criança negra. Para tanto, apresentamos os desafios e limites da ação docente no processo de implementação dessa Lei. A pesquisa de cunho qualitativo utiliza procedimentos metodológicos de análise documental e entrevista semiestruturada. Os estudos de Gomes (2012), Kadlubitski e Junqueira (2010), Cavalleiro (2005), Gonçalves (2001), entre outros, referendaram a perspectiva teórica das análises. Os resultados parciais indicam que passados dez anos de implantação da Lei 10.639/2003, o conhecimento do que ela preconiza é ainda razoavelmente incipiente. Os docentes colaboradores com a pesquisa identificam o objetivo da Lei, mas não reconhecem ou ignoram a presença do preconceito e da discriminação racial no espaço escolar. A pesquisa apontou para a necessidade das redes de ensino desenvolver programas de formação continuada de professores na perspectiva da construção de uma educação pública de qualidade, democrática e antirracista.
\end{abstract}

Palavras-chave: Educação. Relações étnico-raciais. Formação docente.

\begin{abstract}
Abstract: The purpose of this essay is to analyze the methodological procedures and the partial results of a research on Public Policy for the Education of ethnic-racial and the possibilities opened by the Law 10.639/2003, which modifies the LDBENEN and made compulsory the education of History African culture and Afro-Brazilian education systems in Brazil. Reflect on the effectiveness of teaching practices aimed at the recognition and respect for ethnic and racial diversity, to overcome racial discrimination and affirmation of the black child's identity. Therefore, we present the challenges and limitations of the teaching in the process of implementing this law. The research uses qualitative methodological procedures for the analysis of documents and semi-structured interviews. The Gomes studies (2012), and Kadlubitski Junqueira (2010), Cavalleiro (2005), Goncalves (2001), among others, are references to theoretical analysis. The partial results Indicate that after ten years enforcement 10.639/2003 Law, the knowledge is still quite incipient. Teachers research collaborators could identify the purpose of the law, but not acknowledge or ignore the presence of racial prejudice and discrimination in school. The research pointed to the need for school systems to develop continuing education programs for teachers in the perspective of building a quality public education, democratic and anti-racist.
\end{abstract}

Keywords: Education. Ethnic-racial relations. Teacher training. 


\section{INTRODUÇÃO}

$\mathrm{H}$

á mais de uma década, as discussões em torno das questões étnico-raciais contribuíram para repensar sobre o papel da escola e a formação docente no sentido de garantir novos

espaços pedagógicos que propiciem o reconhecimento e a valorização das múltiplas identidades que compõem a população brasileira. As pressões do Movimento Negro Brasileiro foram imprescindíveis nesse processo de luta pelos direitos da população negra e, principalmente, denunciou que o racismo, o preconceito e a discriminação racial estão presentes na sociedade e, consequentemente, nos currículos e práticas escolares.

A luta desse movimento não foi em vão, na medida em que colocou na agenda política do País, a urgência da criação de Políticas Públicas Afirmativas e de diversidade visando à formulação, coordenação e articulação de políticas e diretrizes para a promoção da igualdade racial em todos os setores da sociedade.

No campo da educação, foram implementadas legislações educacionais que colocaram o desafio aos sistemas de ensino, às escolas e aos docentes a desconstrução de uma educação etnocêntrica que historicamente reforçou a transmissão de estereótipos, preconceitos e inferiorização da diferença.

Nessa perspectiva, e como parte do projeto de pesquisa do programa de pós-graduação em educação, o objetivo desse artigo é identificar os avanços e limites da Educação para as Relações Étnico-raciais nas escolas brasileiras. Para tanto, o trabalho foi dividido em três seções. A primeira aponta o arcabouço jurídico e os estudos que fundamentaram a Educação para as Relações Étnicoraciais; a segunda seção tece considerações sobre a prática docente e a diversidade; e, por fim, a última seção realiza diálogo entre prática docente e os limites de sua ação, tendo como referência a análise de questionários aplicados a professores da rede de ensino sulmatogrossense.

\section{EDUCAÇÃO E RELAÇõES RACIAIS: REFLEXÕES SOBRE AS LEGISLAÇõES AFIRMATIVAS}

As questões relacionadas à discriminação racial e educação, tanto no âmbito acadêmico quanto nos demais, têm sido objeto de um número crescente de publicações e estudos, favorecendo a abertura de espaços para discussões e buscas de alternativas para minimizar a discriminação racial e o preconceito nas escolas. Tais vertentes, inauguradas por trabalhos que desmascaram o "mito da democracia racial”, que outrora criara uma cortina de fumaça camuflando o preconceito, têm contribuído para a exploração do assunto. 
Entretanto, quando falamos do racismo enquanto prática cotidiana, o quadro social desde o início do século XX até o momento atual pouco mudou, o que se evidencia no campo educacional através dos índices de alfabetização e escolaridade da população negra e indígena, na discrepância quantitativa e qualitativamente na relação entre elas e outros grupos. Vários estudos denunciaram o preconceito, a discriminação racial e as desigualdades raciais na educação, entre eles os realizados por Munanga (1996), Gonçalves (2000), Gomes (2001) e Cavalleiro (1999), diagnosticando que os negros e índios são penalizados na educação por meio da exclusão do sistema formal de ensino, como também nas outras esferas da vida social.

Com base nesses autores, focamo-nos no que concerne à presença do educador frente a tal realidade; e, para tanto, seguimos os trabalhos de Gonçalves (1985) e Cavalleiro (2000), que analisam que o preconceito racial e a discriminação se proliferam, nas escolas, através de mecanismos ou funcionamento dos rituais pedagógicos, entendido como a materialização da prática pedagógica, vivenciada na sala de aula, a qual exclui dos currículos escolares a história de luta dos negros e/ou índios na sociedade brasileira.

Ainda, Cavalleiro (2000) é mais categórica ao dizer que é flagrante a ausência de um questionamento crítico por parte das profissionais da escola sobre a presença de crianças negras e indígenas no cotidiano escolar. Esse fato, além de confirmar o despreparo dos educadores para relacionarem com os alunos negros e indígenas evidencia, também, seu desinteresse em incluí-los positivamente na vida escolar, pois interagem com eles diariamente, mas não se preocupam em conhecer suas especificidades e necessidades, o que permite concluir que

\begin{abstract}
O silêncio da escola sobre as dinâmicas das relações raciais tem permitido seja transmitida aos (as) alunos (as) uma pretensa superioridade branca, sem que haja questionamento desse problema por parte dos (as) profissionais da educação e envolvendo o cotidiano escolar em práticas prejudiciais ao grupo negro. Silenciar-se diante do problema não apaga magicamente as diferenças, e ao contrário, permite que cada um construa, a seu modo, um entendimento muitas vezes estereotipado do outro que lhe é diferente. Esse entendimento acaba sendo pautado pelas vivências sociais de modo acrítico, conformando a divisão e a hierarquização raciais (CAVALLEIRO, 2006, p.23).
\end{abstract}

Esse quadro proporcionou aos movimentos sociais ao longo da história, combustível necessário para se empenharem em construir o que hoje chamamos tão naturalmente de cultura da diversidade, ou diversidade étnico-racial, através do paulatino levante de questões relacionadas à discriminação racial e educação, tanto no âmbito acadêmico quanto nas demais instituições, favorecendo aos poucos a abertura de espaços para discussões e busca de alternativas que minimizem a discriminação racial e o preconceito, independente de forma, nas nossas escolas brasileiras. 
Essa transformação se traduziu, em uma das suas instâncias, de certa forma, nas legislações hoje vigentes no cenário educacional, a Leis 10.639/03 que alterou a LDBEN (Lei 9.394/96) e incluiu no currículo escolar oficial a obrigatoriedade do ensino de História e Cultura Afro-Brasileira e de África, e a Lei 11.645/08 que modificada a Lei 10.639/03, e estabelece as diretrizes e bases da educação nacional, para incluir no currículo oficial da rede de ensino a obrigatoriedade da temática "História e Cultura Afro-Brasileira e Indígena”.

Essas legislações, de certa forma, buscam efetivar o que é de direito dos brasileiros: o conhecimento indiscriminado de sua cultura e valorização de sua identidade. No que tange à luta por esse direito, a legislação brasileira, com aporte específico à Constituição Federal de 1988, em seu artigo 5. ", "instituiu a discriminação racial como prática de crime inafiançável e imprescritível, sujeito à pena de reclusão, nos termos da lei”. No que se refere especificamente à Educação, o artigo 27, inciso I, é destacado que os conteúdos curriculares da Educação Básica deverão observar "a difusão de valores fundamentais no interesse social, aos direitos e deveres dos cidadãos de respeito ao bem comum e a ordem democrática”.

Com ciência dessa realidade, e enxergando os reflexos das transformações no cenário educacional, defendemos aqui que uma educação para a diversidade racial brasileira não pode, sem dúvida, prescindir do respaldo legal, mas a legislação só se concretiza no espaço escolar em uma dinâmica curricular e da sala de aula que privilegie uma educação anti-racista com conteúdo antiracista (OLIVEIRA, 2009). Para que isso se efetive, os profissionais da educação, com enfoque aos docentes, necessitam de uma concepção que lhes garanta o domínio dos conteúdos a ensinar, no sentido amplo do termo, que inclua os valores que tal tipo de educação deverá privilegiar e de uma pedagogia que lhe permita manipular tais conhecimentos e privilegiar tais valores, colocando-os assim a serviço da equidade racial, cultural e de gênero.

Partindo dessa concepção, propomo-nos realizar um diálogo acerca da definição do trabalho docente para com as coletividades, enfatizando sua importância para a construção de posições antiraciais a partir do processo de troca de conhecimentos, que aqui ousamos inserir no entendimento de práxis, bem como da compreensão do papel do educador no processo de formação dos atores sociais.

\section{A PRÁTICA DOCENTE NA PERSPECTIVA DA DIVERSIDADE}

Na educação pública, várias têm sido as práticas pedagógicas voltadas para a diversidade étnico-racial existentes em todo o país. Há relatos de experiências mais enraizadas como a inserção da Lei 10.639/03, bem como da 11.645/08 nos Projetos Pedagógicos, trabalhos conjuntos com a 
comunidade, movimento negro, projetos interdisciplinares, comemoração do dia nacional da consciência negra, do índio, estudos sistemáticos sobre o continente africano, cultura e artesanato indígena, projetos realizados com a participação dos estudantes, dentre outros.

No entanto, como demonstra Kadlubitski e Junqueira (2010, p. 184), mesmo com os avanços nos documentos oficiais do Brasil, existem hoje "uma presença difusa e confusa da diversidade na prática pedagógica, não existindo uma orquestração de propostas, projetos e práticas”. Os trabalhos produzidos na área trazem declarações de tipo normativo, explanando que, para alcançarem a dimensão objetiva, as práticas e ações pedagógicas necessitam efetivamente incorporar a formação de profissionais da Educação nos hábitos e costumes das práticas sociais.

Posição essa justificada pelo entendimento de práticas sociais e pedagógicas como não neutras e que por isso devem ser consideradas à ótica das relações que se estabelecem no espaço escolar, pois, parafraseando Certeau (1994, p.202), “espaço é um lugar praticado” e, dessa forma, defende-se que no espaço escolar os embates entre os diferentes sujeitos que o compõem são frequentes e, no que tange à cultura, essas diferenças entre os professores e os alunos, e entre alunos e alunos, influenciam nas relações estabelecidas.

Nessa linha, identifica-se que as pesquisas destinadas à discussão sobre o significado do trabalho docente diante da diversidade de sujeitos que se apresentam no interior das escolas se fundamentam num espaço muito profícuo e vem demonstrando vitalidade cada vez maior no cenário bibliográfico, devido à importância presente de compreender no que se embasa o ser docente com o qual estamos envolvidos social e cotidianamente, bem como as particularidades de suas ações.

Esse ser docente passa a ser entendido como ator de uma ação mediadora entre a formação do aluno na vida cotidiana, na qual ele se apropria de forma espontânea da linguagem, dos objetos, dos usos e dos costumes, e a formação do aluno nas esferas não cotidianas da vida social, dando possibilidade de acesso a objetivações como ciência, arte, moral, etc, e possibilitando, ao mesmo tempo, sua postura crítica para com as diversidades, através do que é denominado de educação formal. (DUARTE, 1993)

Essa mediação entre o aluno e a cultura apresenta características distintas, pois, para Basso (1995), a educação formal é qualitativamente diferente de outras formas de educação, por ter como finalidade específica propiciar a apropriação de instrumentos culturais básicos que permitam elaboração de entendimento da realidade social e promoção do desenvolvimento individual, o que adjetiva a atividade pedagógica do professor como um conjunto de ações intencionais, conscientes, dirigidas para um fim específico. 
Na ótica da pluralidade que compõe o universo do trabalho docente, e visando entender as nuances desse trabalho, vislumbrando o docente também como indivíduo social, buscamos expor a prática docente no intento das relações étnico-raciais como parte de uma ação pedagógica. Para tanto, partimos primeiramente do entendimento do termo “ação”, utilizado por vezes no presente trabalho, e que tem sua definição pautada nos trabalhos de Tardif e Lessard (2012). Para os autores, “Ação” no contexto do trabalho docente deve ser entendida como o próprio processo de ensinar, não se definindo apenas em fazer algo, mas fazer com alguém alguma coisa significativa: o sentido que se permuta em classe, as significações comunicadas, reconhecidas e partilhadas (TARDIF e LESSARD, 2012, p.249); uma atividade comunicada e direcionada, que resulte não apenas no objetivado pelo planejamento, indo além dos muros da escola.

Dentro dessa ação, o professor ao comunicar-se, o faz não apenas de maneira a trabalhar a capacidade individual de aprender de cada indivíduo, mas sim, com a habilidade coletiva de receber a comunicação e transformá-la em significação.

E assim como atividade direcionada primeiramente a um coletivo, graças à ação de um sujeito que fala, a definição de trabalho docente deve partir também da concepção de atividades humanas individuais e coletivas, no qual o indivíduo como integrante coletivo de um todo participa ativamente no processo de construção do conhecimento, com práticas e instrumentos específicos, por ser ele, como defende Vasconcellos (2003), interativo e possuir características próprias das particularidades ontológicas de existir.

Particularidade esta compreendida a partir da definição de identidade, que para Souza (2012), é una e múltipla, simultaneamente, pois se trata de um processo dinâmico que reflete constante transformação em que o eu e o outro mantém uma interação dialética, responsável por organizar cada experiência pessoal que tem como representação de um mundo simbólico (SOUZA, 2012, p. 137).

Essa relação da concepção do objeto e suas relações, ora individual, ora coletivo, resulta na necessidade de uma análise direcionada do conceito de trabalho docente, centrando na perspectiva da ação-reflexão, o caminho mais seguro para isso, pois parte do consenso de que o professor trabalha com e sobre coletividades humanas, e esse trabalho tem a consequência de transformar as ações do professor no próprio processo de interações com os grupos de alunos, ao passo em que os alunos também interagem entre si, como defende Tardif e Lessard (2012), resultando numa definição que vai além do previsto nas ementas escolares.

Esse processo, denominado de “ação-reflexão”, tende a fazer parte integrante do processo de formação docente, definindo inicialmente as formas de ensinar, de perceber os alunos - o aluno - e a natureza dos conhecimentos a serem construídos a partir do momento em que se propõe fazer, 
vertendo numa perspectiva que compõe esse trabalho, pois citando Gadotti (2012), a diversidade cultural é a riqueza da humanidade, e para cumprir sua tarefa humanista, o professor precisa mostrar aos alunos que existem outras culturas além da sua; e isso somente se efetiva a partir da reflexão sobre sua ação.

No entanto, mesmo nessa perspectiva, os objetivos traçados para o desempenho do trabalho docente, na premissa do indivíduo coletivo, devem estar conectados com os conhecimentos dos alunos, da sociedade, das interfaces dos conteúdos e das concepções filosóficas que enraízam as condições naturais e sociais dos alunos como objeto, pois estes não são apenas seres psicobiológicos, como explica Tardif e Lessard (2012); são também seres sociais parcialmente definidos por uma situação socioeconômica, seus valores, suas crenças, seus interesses, e portadores de indeterminações e de diferenciações: e em parte, eles sempre escapam as regras gerais, as leis coletivas, aos mecanismos inventados para enquadrá-los e controlá-los (TARDIF e LESSARD, 2012, p.70).

Nessa base, Gonçalves e Soligo (2006, p. 27), apostam numa ação docente intercultural e antirracista, onde a questão da identidade e da diferença sejam discutidas e entendidas no contexto das relações de poder, dentro e fora da escola, sem desconsiderar o aluno como indivíduo social.

E no que se refere à docência, em síntese, pode-se entender que o educador também, como ser interativo, é fruto da própria relação com seu trabalho, pois como bem mostra Vasconcellos (2003) o trabalhar, dentro da concepção de trabalho docente, não é apenas transformar seu objeto em outra coisa, outro objeto, mas é envolver-se ao mesmo tempo numa práxis fundamental em que o trabalhador também é transformado por seu trabalho.

Assim sendo, para trilhar o entendimento dessa ideia, tanto nas nuances do objeto aluno como do docente interativo, nos reportamos ao conceito de práxis, que aqui pode ser muito bem aplicado. Práxis, na definição filosófica do termo, para Abbagnano (1998) é a transcrição da palavra grega que significa ação, e na terminologia marxista designa o conjunto de relações de produção e trabalho, que constituem a estrutura social, e a ação transformadora que a revolução deve exercer sobre tais relações (ABBAGNANO, 1998, p. 786). A expressão “ação transformadora” se aplica bem ao contexto educativo da práxis, pois para Vasquez $(1997$, p.5) práxis, nesse intento, é entendida como sendo a categoria central da filosofia que se concebe ela mesma não só como interpretação do mundo, mas também como guia de sua transformação, pois a práxis aí é um caminho, uma das importantes manifestações de uma postura transformadora.

A postura transformadora, que se respalda na interpretação da ação e na idéia de trabalho, nos remete então à discussão dos elementos da definição de trabalho, da qual partindo da teoria de 
Tardif e Lessard (2012), têm a docência centrada no “objeto humano” e suas ações, se desenvolvendo com alunos, sobre alunos e para alunos.

Entretanto, com a realidade atual centrada na diversidade de sujeitos que se apresentam no interior da escola, segundo Oliveira (2012), é fundamental o redimensionamento do olhar desse educador, convergente a uma mudança de linguagem, reflexão da prática, e uma ação interdisciplinar voltada à construção de um perfil profissional vinculado à pesquisa no espaço escolar - ação/reflexão, o que na ótica das relações etnicorraciais remete ao entendimento de uma desconstrução de noções e concepções apreendidas durante os anos de formação dos professores.

E é esta ação-reflexão diante do coletivo por parte do professor que se traduz como a real definição de práxis no cerne da educação, esta que é considerada como uma ação transformadora, visto que o trabalho com uma coletividade tem a consequência de transformar as ações do professor em interações com um grupo em que os alunos interagem entre si, pois desta maneira é possível estabelecer um diálogo entre estes dois mundos (professor-aluno), dando a oportunidade para que o professor possa repensar suas maneiras de trato com o educar.

Essa participação ativa aluno/professor, aluno/aluno, não apenas promove a superação dos antigos fazeres pedagógicos, como a mudança daquela atitude amorfa, bem como traz à tona uma imprescindível conscientização por parte do educador que atua no Ensino Fundamental de seu compromisso com a educação do sujeito. Isso implica uma nova prática pedagógica, apoiada no conhecimento científico, em concepções definidas, na segurança, no envolvimento com a formulação de um projeto pedagógico adequado ao contexto escolar (OSÓRIO, 2003).

A prática pedagógica, aqui exposta, remete que o educador como sujeito de uma prática intencionada, deve combinar o seu fazer pedagógico com a reflexão, este além da própria concepção de ação-reflexão o que, por conseguinte, implica buscar alternativas para mudanças, tomar decisões para a inovação da prática educacional, defendida por Osório (2003), resultando no poder da ação pedagógica em se consolidar realmente numa prática transformadora.

Entretanto, conforme Vasconcelos (2003), vale lembrar também que a efetiva mudança de prática pedagógica não se faz apenas com uma simples alteração de técnicas ou recursos. O caminho transformador é diferente, pois se trata de uma reconstrução do próprio ser docente que, como tal, deve partir do que o sujeito tem de história pessoal e profissional, e em se tratando do sujeito coletivo, há que se levar em conta, inclusive, sua história institucional e social, e somente deste modo haverá possibilidade de enraizamento de uma nova postura e, por tabela, uma nova prática.

Isso, no entendimento de Valente (2006), só é possível se pensado no contexto da problemática da docência em geral, na qual se identifica a possibilidade de superação do dualismo 
entre prática e teoria, politizando o debate acerca das relações étnico-raciais, já que esta questão envolve relações de poder e conflitos históricos nas relações sociais brasileiras, nas quais se busca articular valores universais com as especificidades étnico-culturais.

A resultante desse processo será perceptível quando o professor conseguir trabalhar a alteridade dentro da sala de aula, fazendo com que os alunos reconheçam a figura do outro, sabendo respeitar o espaço individual de cada ser, sem perder a essência coletiva, pois é dentro da sala de aula que acontecem interações significativas e essas interações procedem de significações e interpretações elaboradas constantemente pelos autores para compreender a ação dos outros e tornálos compreensíveis aos outros, o que finda por concretizar a identidade tanto do educador, como dos alunos e assim vincular a teoria e prática a partir de um elo comum, a sala de aula.

Assim, é válido dizer que nesse cenário o papel do professor deixa de ser visto apenas como de um agente exclusivo de informação e formação dos alunos, centrando agora sua principal característica como a de ser o mediador das interações entre os alunos e destes com o novo, o diverso, o diferente, tornando-se fundamental na promoção de avanços do desenvolvimento do indivíduo.

Ou seja, seu objetivo é o desenvolvimento de um trabalho de acordo com um conceito progressista de educação; a relação educador/educando exige, por parte dos educadores, uma atitude de respeito, valorização, confiança e disponibilidade para ajudar o aluno na construção de novos conhecimentos, contribuindo para a preparação de cidadãos participativos, autônomos, críticos e reflexivos. (OSÓRIO, 2003)

Dessa forma, entende-se que não é possível discutir o trabalho docente à premissa da diversidade étnico-racial, cultural, social, de orientação sexual, religiosa etc, apenas pelo seu caráter objetivo, como métodos ou ferramentas, ou utilizando como escudo de defesa as bases que a própria legislação ofertada, pois tal atitude conduz à crença na possibilidade de falar em educação desconsiderando a importância da subjetividade existente nas “atividades simples” do próprio processo do ensinar, e da compreensão da individualidade coletiva presente no processo educativo.

Discutir ensino no mundo contemporâneo implica refletir acerca das especificidades dos professores e dos alunos, suas intenções durante o processo e, também, das condições subjetivas existentes que permitem, efetivamente, aos docentes, a viabilização de suas aspirações.

\section{EDUCAÇÃO E DIVERSIDADE ÉTNICO-RACIAL: ENTRE O FORMAL E O REAL}

Com afinco interesse nas discussões acerca da inserção do que se defende como diversidade cultural, na construção do presente texto buscou-se refletir sobre a ação docente nas escolas à ótica 
das práticas pedagógicas a partir da capacitação e atualização de conceitos e métodos sujeitos às mudanças legais.

Pautamos que identificar a sala como reduto de uma construção social é, a priori, o passo principal para o trabalho com a diversidade étnico-racial. É consenso dos pesquisadores em educação a existência de uma identidade específica em cada indivíduo, mas a possibilidade de trabalhar em sala com as culturas que convergem numa concepção única de cultura no país, partindo da ótica das diversas identidades, ainda significa algo muito dispendioso.

Nesse entendimento e a fim de mensurar como essa mudança, no teor formativo docente, está se refletindo em sala de aula, buscamos trabalhar com entrevista em formato de questionários aplicados a um grupo de pós-graduandos que cursam uma Especialização para profissionais da Educação.

Visamos através destes questionários, enfatizando que os entrevistados são educadores dos anos iniciais do ensino fundamental, identificar como a legislação atual vigente para a valorização étnico-racial vem sendo tratada dentro do cenário escolar.

Para análise, e com embasamento teórico de Kadlubitski e Junqueira (2010), partimos da premissa de que a educação escolar é uma prática social que pode contribuir para a inclusão dos cidadãos, mas pode também se configurar como um processo contrário, no qual “os saberes e conhecimentos que ocorrem nas salas de aula constituem uma forma de construir significados, reforçar e confrontar interesses sociais, formas de poder, de experiência, que têm sempre um significado cultural e político” (SANTOMÉ, 1995, p. 166).

A cargo dessa bagagem teórica e buscando a compreensão de como refletem na ação docente os aportes legais, o presente artigo, como parte de um projeto de pesquisa que discute políticas públicas para a educação das relações étnico-raciais a partir das possibilidades abertas pela lei 10.639/03, defendendo a necessidade em identificar o nível de interação dos professores com a lei 10.639, trabalhou-se com quatro questões aplicadas a 16 educadores.

Os questionamentos pautavam-se na Lei 10.639/03 e na presença de resquícios de discriminação racial no ambiente escolar, centrando acepção da ação-reflexão docente a partir da prática pautada nas normativas escolares. As questões aplicadas foram: O que você sabe sobre a Lei 10.639/2003?; Existe na escola situações que envolvem relatos de preconceito e discriminação racial? (explicito ou não, por exemplo, em forma de brincadeiras, apelidos ou bullying)?; Quais as dificuldades para implementação da Lei 10.639/203 nas escolas de um modo geral?; Você já participou de algum curso de formação continuada sobre a Educação pra as relações étnicoraciais e para a implementação da Lei 10.639/2003? 
Em contato com os dados coletados, percebemos que o conhecimento legislativo teórico acerca da necessidade de reconhecimento e valorização das diversas culturas que compõem a sociedade brasileira se faz presente na rotina docente, estando no contato com os livros didáticos e os Planos Pedagógicos, o principal responsável pela disseminação dos caminhos trilhados para “heterogeneização" cultural, conforme Cavalleiro (2010). Ponto este evidenciado quanto às respostas para o primeiro questionamento, na qual todos os profissionais puderam definir, de maneira diversa, qual o teor da referida lei.

Em sequência, o segundo item questionado, expôs a existência de atitudes de discriminação racial no ambiente escolar, estas mascaradas, muitas vezes, em forma de brincadeiras, piadas, bullying, etc. Dos 16 questionários, apenas 5 relataram não ter presenciado pelo menos alguma vez formas de discriminação racial, sendo 2 deles justificados pela existência de preconceito "somente" para com a orientação sexual. Dados que nos levam a pensar que, mesmo com ações direcionadas à aquisição de valores culturais diversos, a escola continua a perpetuar atitudes arcaicas.

Atitudes, poucas vezes trabalhadas em sala de aula, que acabam por solidificar uma posição passiva da escola para com o preconceito racial; e essa posição, chamada de silêncio escolar por Cavalleiro (2005), finda por perpetuar uma cultura preconceituosa dentro da própria escola, e sendo ela uma extensão da sociedade em que está inserida, forma atores sociais com uma “eterna” postura de preconceito e discriminação para com o diverso; e podemos dizer isso não somente no que tange àa questão de cor, mas também de gênero, culto etc.

Ao incitar sobre as dificuldades para a implementação da lei, 02 entrevistados direcionaram ao livro didático a principal barreira existente, entendendo este como ferramenta de manipulação do governo, no qual se "embute quais os caminhos que a educação deve trilhar e põem o educador para levar as crianças pelas mãos”, citando um dos questionários. Em contrapartida, uma das respostas centrou no livro didático a principal ferramenta de disseminação do que a lei elenca, pois este - o livro - traz de forma direcionada o que deve ser entendido como cultura afro-brasileira, e utiliza-se de marcos (como o dia da Consciência Negra) como referência para a consumação do preconizado.

O interesse por parte do profissional também foi pautado como fator preponderante, este com um total de 3 respostas, reforça que o educador, como individuo e ator social, deve também buscar sua atualização continua para com a educação nacional pois, à medida que entende as carências sociais, deve embasar-se teoricamente em formas de defesa e qualificação pautado, é claro, na ciência dos reflexos de suas ações.

A sociedade, esta na qual a instituição escolar está inserida e da qual capta características deterministas, é tida como referência também para com as dificuldades de implementação da legislação em pauta, somando um quantitativo de 3 apontamentos. Para os educadores, a sociedade, 
enraizada em valores intrínsecos em sua própria essência, acaba por formar uma barreira, mesmo que subjetiva, para a formação de uma consciência social pautada na diversidade cultural, seja ela étnica, religiosa ou de gênero, estando sempre chamuscada de pequenos / grandes preconceitos, entendidos como naturais e refletidos na postura do educando, e muitas vezes do educador, para com tudo o que é diferente.

A grande dificuldade para a implementação, tendo em vista os 6 apontamentos existentes, expõe a deficiência existente no campo das capacitações profissionais as quais os docentes devem ter acesso. Fato esse evidenciado também quando do trato com o último item questionado.

Ao falar sobre a participação dos entrevistados em cursos de capacitação que abordavam tal temática, dum quantitativo de 16 docentes que responderam o questionário, apenas 4 estiveram em contato com a legislação 10.639/03, sendo que um realizou a capacitação externa à escola. Dos 12 participantes, 2 mencionaram ter conhecido a lei durante a graduação.

Fator alarmante, diga-se de passagem, pois à perspectiva de uma análise da ação profissional pautada na formação docente, tendo em vista que muitos destes profissionais tenham se graduado antes dos anos de 2003, nos possibilita identificar uma tendência em seguir apenas o que o livro didático tem a oferecer, sem conhecer as transformações sociais que convergiram no que hoje é refletido na escola.

Em síntese, mesmo que a legislação, as normativas governamentais, bem como os programas direcionados à questão da diversidade étnico-racial atuem de forma preponderante no cenário educacional, podemos ousar dizer que, ainda sim, isso não se faz suficiente se não houver uma massificação de ações, principalmente no que se refere à formação continuada dos docentes, pois os educadores estão saindo das universidades com uma quantidade significativa de conceitos em seus currículos, mas que ainda não são suficientes para atuarem de forma satisfatória no que se refere ao trato da diversidade no ambiente escolar.

A legislação em si não faz uma mudança; e o fato de os professores não participarem de formação para com o trato dessas mudanças em sala é, no mínimo, característica de que o poder externo à escola entende que a inserção no livro didático do que a lei prepondera já é o suficiente. Assim, como é possível trabalhar a alteridade, a práxis ou qualquer outra forma de valorização de identidade se não há base na escola para isso? Como o educador conseguirá identificar alguma forma de discriminação racial, e trabalhar isso em classe para sua erradicação, se também a pratica?

Enfim, a ação docente sozinha não consegue lutar contra o que está enraizado nos jardins da sociedade. É ciência que a academia hoje, através de pesquisas e trabalhos relacionados, almeja uma transformação social. Mas devemos nos ater no ideário que, somente através da teoria não se pode alcançar os objetivos elencados pela lei. A escola é um espaço propício para que se discutam 
as diferentes culturas, sociais e raciais. Mas, para tanto, é fundamental que se construa um caminho, e este se faz com a abrangência totalitária da sociedade, na qual é essencial uma visão minimalista de todos os entraves que o individuo, seja este coletivo ou não, possa pôr para com o andar dessas transformações.

\section{CONSIDERAÇÕES FINAIS}

Voltando nossos olhares para as escolas de educação básica, várias são as razões elencadas pelos atores dos sistemas de ensino para a não implementação de educação anti-racista, das quais ganham destaque: o desconhecimento das Leis 10.639/03 e 11.645/08; a falta de formação especifica para as professoras e professores; a inexistência de livros e materiais didáticos que correspondam ao conteúdo proposto e a falta de recursos para investimento.

Nesse entendimento, como via de escape, podemos defender a possibilidade de debates permanentes entre os docentes à premissa de sua ação pois, num processo educativo de trocas e inter-relações de conhecimentos, se converge um modelo pedagógico, no qual os professores podem exercitar novas sociabilidades étnico-raciais e novas posturas nas suas subjetividades.

Entretanto, os gargalos para uma transformação na ação docente vão mais além, pois a questão curricular se desdobra na necessidade de uma nova política educacional de formação inicial e contínua, para reverter positivamente às novas gerações, uma nova interpretação da história e uma nova abordagem da construção de saberes pois, de outra forma, continuaremos numa perspectiva de dúvida e incapacidades teóricas e práticas de enfrentar os conflitos iminentes das discussões étnicoraciais na educação.

Existe hoje uma necessidade indubitável de se incluir nos currículos e nas práticas pedagógicas as diferenças culturais de cada povo e cada raça para dar sentido e tornar possível a discussão da diferença racial no cotidiano escolar, tornando essas diferenças uma possibilidade de respeito e diálogo com as diversas identidades presentes cotidianamente na sala de aula, e fora dela.

Deste modo, como considerações parciais de nossa pesquisa, deixamos como pretensão de produções derivadas da proposta exposta pelo programa de pós-graduação da qual centramos nossos investimentos acadêmicos, investigar como estão sendo implementadas as políticas de valorização étnico-racial nas escolas sulmatogrossenses, no aspecto da construção do currículo voltado para a diversidade, não do ponto de vista dos legisladores ou dos gestores das políticas públicas, mas a partir das experiências vividas nos espaços escolares, nas opiniões, valores, conceitos, idéias, preferências, concepções de professores e educandos que ocupam esses lugares, abrindo espaço 
para novos vieses no que tange as diversidades, das quais se caracterizam a composição social brasileira.

\section{REFERÊNCIAS}

ABBAGnANO, N. Dicionário de Filosofia. Tradução Alfredo Bosi. 2. ed. São Paulo: Martins Fontes, 1998.

BRASIL. Presidente da República. Lei 10639/2003. Diário Oficial da União. Brasília, de 10 de janeiro de 2003.

BRASIL. Presidente da República. Lei 11645/2008. Diário Oficial da União. Brasília, de 10 de março de 2008.

- Diretrizes Curriculares Nacionais para a Educação das relações Étnico - Raciais e para

o Ensino de História e Cultura Afro-Brasileira e Africana. Secretaria Especial de Políticas de Promoção da Igualdade Racial. Brasília: MEC, 2005.

BASSO, I.S. Formação de professores: Contribuições da perspectiva histórico-social. Anais. Simpósio Formação de Professores: Tendências Atuais. São Carlos, UFSCar, 1995.

CAVALLEIRO, E. Discriminação racial e pluralismo em escolas da cidade de São Paulo. In: Educação anti-racista: caminhos abertos pela Lei Federal n.10.639/2003. Secretaria de Educação Continuada, Alfabetização e Diversidade. - Brasília: Ministério da Educação, 2005.

DUARTE, N. A individualidade para si. Campinas: Autores Associados, 1993.

GOMES, N. L. et al. Identidades e Corporeidades Negras: Reflexões sobre uma experiência de formação de professores/as para a diversidade étnico-racial. Belo Horizonte: Autêntica, 2006.

GONÇALVES, L.A.O. Negros e educação no Brasil. In: LOPES, E.M.T.; FARIA FILHO, L.; VEIGA, C.G. (Org.). 500 anos de educação no Brasil. Belo Horizonte: Autêntica, 2000. p. 325346. 
KADLUBITSKI, L.; JUNQUEIRA, S. Diversidade cultural na formação do Pedagogo. VIDYA, v. 30, n. 1, p. 25-41, jan./jun., 2010 - Santa Maria, 2010.

MUNANGA, K. Uma abordagem conceitual das noções de raça, racismo, identidade, etnia. Niterói: EdUFF, 2000.

OLIVEIRA, I. B. Boa Ventura e a Educação. Belo Horizonte: Autêntica, 2012.

OSORIO, A. M. N (Org.). Trabalho docente: os professores e sua formação. Campo Grande, MS: Ed. da UFMS, 2003.

SANTOMÉ, J. T. As culturas negadas e silenciadas no currículo. In: SILVA, T. T. (Org.). Alienígenas em sala de aula: uma introdução aos estudos culturais em educação. Petrópolis: Vozes, 2003.

SOUZA, M. E. V. Educação étnicorracial brasileira: uma forma de educar para a cidadania. In: MIRANDA, C. LINS, M.R.F. COSTA, R.C.R. Relações Étnicorraciais na escola: desafios teóricos e práticas pedagógicas após a lei n. 10.639. Rio de Janeiro: Quartet editora, 2012.

TARDIF, M. LESSARD, C. O trabalho docente: elementos para uma teoria da docência como profissão de interações humanas. Tradução de João Batista Kreuch. Petrópolis, RJ: Vozes, 2012.

VALENTE, A. L. Ação Afirmativa, relações raciais e educação básica. Revista Brasileira de Educação. n. 28. Rio de Janeiro: jan./fev./mar./abr. 2005.

VASCONCELlOS, C. S. Para onde vai o professor? Resgate do professor como sujeito de transformação. 10. ed. São Paulo: Libertad, 2003.

VAZQUEZ, A. S. Filosofia da Práxis. 2. ed. Rio de Janeiro: Editora Paz e Terra, 1977. 